\title{
Efficiency analysis of wide band-gap semiconductors for two-level and three-level power converters
}

\author{
$1^{\text {st }}$ David Lumbreras \\ Department of Electronic Engineering \& R\&D Power Electronics \\ Technical University of Catalonia \& Circutor \\ Terrassa, Spain \\ david.lumbreras@upc.edu \& dlumbreras@circutor.com \\ $3^{\text {rd }}$ Juan Mon \\ Department of Electronic Engineering \\ Technical University of Catalonia \\ Terrassa, Spain \\ juan.mon@upc.edu \\ $4^{\text {th }}$ Eduardo Gálvez \\ $R \& D$ Power Electronics \\ Circutor \\ Viladecavalls, Spain \\ egalvez@circutor.com
}

\author{
$2^{\text {nd }}$ Jordi Zaragoza \\ Terrassa, Spain \\ $5^{\text {th }}$ Alfonso Collado \\ Technological Innovation \\ Circutor \\ Viladecavalls, Spain \\ acollado@circutor.com
}

Department of Electronic Engineering

Technical University of Catalonia

jordi.zaragoza-bertomeu@upc.edu

\begin{abstract}
Power devices based on wide band-gap materials are emerging as alternatives to silicon-based devices. These new devices allow designing and building converters with fewer power losses, and are thus more highly efficient than traditional power converters. Among the wide band-gap materials in use, silicon carbide ( $\mathrm{SiC}$ ) and gallium nitride (GaN) devices are the most promising because of their excellent properties and commercial availability. This paper compares the losses produced in two-level and three-level power converters that use the aforementioned technologies. In addition, we assess the impact on the converter performance caused by the modulation technique. Simulation results under various operating points are reported and compared.
\end{abstract}

Index Terms-Gallium Nitride (GaN), Losses, Modulation Techniques, Neutral-Point Clamped Converter (NPC), PLECS, Silicon, Silicon Carbide (SiC), Wide Band-Gap Semiconductors.

\section{INTRODUCTION}

Wide band-gap (WBG) semiconductors have some properties that provide advantages over the classic silicon $(\mathrm{Si})$ power devices [1], [2]. Silicon carbide $(\mathrm{SiC})$ and gallium nitride $(\mathrm{GaN})$ are the two WBG semiconductors that are starting to have impact on several power electronics applications, such as server supplies, mobile device chargers, EV vehicles, aerospace applications, HVDC transmission, energy storage systems and wireless chargers [3]-[5]. These two materials make it possible for devices to be manufactured with lower specific on-resistance [1], thus resulting in power devices with better performance and fewer power losses than conventional silicon devices [2].

One of the most attractive properties of WBG semiconductors is their capacity to work at high switching frequencies [6]. An important part of the generated EMIs appears at the switching frequency, so raising the switching frequency allows using
TABLE I

PROPERTIES OF THE SEMICONDUCTORS

\begin{tabular}{|c|c|c|c|}
\hline Property & $\mathbf{S i}$ & 4H-SiC & GaN \\
\hline $\begin{array}{c}\text { Energy Gap } \\
(\mathrm{eV})\end{array}$ & 1.12 & 3.2 & 3.4 \\
\hline $\begin{array}{l}\text { Electric breakdown field } \\
(\mathbf{k V / c m})\end{array}$ & 300 & 3500 & 3300 \\
\hline $\begin{array}{l}\text { Saturated electron velocity } \\
\qquad\left(10^{7} \mathrm{~cm} / \mathrm{s}\right)\end{array}$ & 1 & 2 & 2.2 \\
\hline $\begin{array}{l}\text { Electron mobility } \\
\left(\mathrm{cm}^{2} / \mathrm{V} \cdot \mathrm{s}\right)\end{array}$ & 1300 & 950 & 1500 \\
\hline $\begin{array}{l}\text { Hole mobility } \\
\left(\mathrm{cm}^{2} / \mathrm{V} \cdot \mathrm{s}\right)\end{array}$ & 600 & 115 & 850 \\
\hline $\begin{array}{l}\text { Thermal conductivity } \\
(\mathrm{W} / \mathrm{cm} \cdot \mathrm{K})\end{array}$ & 1.5 & 3.8 & 1.3 \\
\hline
\end{tabular}

smaller output filters [7]. Using smaller passive filters may cheap the cost of the converters. The properties of $\mathrm{Si}, \mathrm{SiC}$ and GaN [3], [8]-[11] are presented and compared in Table I.

The high electric breakdown field of $\mathrm{GaN}$ and $\mathrm{SiC}$ semiconductors allow them to operate at high voltages [8]. GaN has the highest electron mobility and saturation electron mobility. These two properties make GaN transistors the most suitable for high-frequency operations [6]. However, $\mathrm{SiC}$ has the highest thermal conductivity and $\mathrm{GaN}$ has the lowest, even when compared with $\mathrm{Si}$. Hence, $\mathrm{SiC}$ is able to work at extremely high temperatures [10]. Since the thermal conductivity of $\mathrm{GaN}$ is very low, heat management is crucial when using $\mathrm{GaN}$ [3], [8].

WBG semiconductors also have important drawbacks. One of these is the lack of high-temperature packaging techniques [3]. Hence, even though $\mathrm{SiC}$ offers excellent thermal conductivity, $\mathrm{SiC}$ devices have maximum operating temperatures of about 
$125-150{ }^{\circ} \mathrm{C}$, which is similar to $\mathrm{Si}$. Another disadvantage of WBG semiconductors is that their fabrication processes are not mature. Manufacturing $\mathrm{SiC}$ devices is tougher than manufacturing $\mathrm{GaN}$ enhancement-mode high electron mobility transistors (e-HEMTs) [6]. In fact, $\mathrm{SiC}$ wafers are usually smaller than $\mathrm{GaN}$ wafers [6], [12] and, therefore, the fabrication cost is higher for $\mathrm{SiC}$ devices. Thus, in the near future, when $\mathrm{GaN}$ devices become more popular, GaN e-HEMTs may be cheaper than SiC MOSFETs. Nowadays, WBG semiconductors are expensive [3], but recent agreements between power device manufacturers and foundries may reduce the cost of these devices [13].

Although the properties of WBG semiconductors have been widely studied, no studies have ever compared their impact on efficiency in different topologies of power converters. SiC and $\mathrm{GaN}$ are struggling to become the dominant semiconductor technology in the industry, but it remains unclear when it is better to use one or another. This paper presents a comparative study on the efficiency of two-level and three-level power converters based on $\mathrm{Si}, \mathrm{SiC}$ and $\mathrm{GaN}$.

To perform this comparison, we analyse a voltage source inverter (VSI) and a neutral point clamped converter (NPC) that are aimed to inject energy to the grid.

For two-level converters, we use two types of power devices for the analysis: Si IGBTs and SiC MOSFETs. GaN power devices are excluded from this analysis because they can only withstand voltages of up to $650 \mathrm{~V}$. However, some manufacturers are beginning to commercialize GaN-based transistors that are able to work with voltages of up to $1200 \mathrm{~V}$, such as the VM40HB120D. Fig 1. shows the half-bridge topologies used in the two-level converters.

For three-level converters, we analyse the impact of four halfbridge configurations. First, we study an NPC converter made using only Si devices. Second, we perform the same analysis using $\mathrm{SiC}$ devices. Then, we study an NPC converter that uses $\mathrm{GaN}$ e-HEMTs and $\mathrm{SiC}$ clamping diodes. $\mathrm{GaN}$ diodes are omitted because they are not commercially available. Finally, we analyse a GaN-based NPC converter like the one mentioned previously, but with $\mathrm{SiC}$ diodes connected in antiparallel with GaN e-HEMTs. The half-bridges of the aforementioned converters are illustrated in Fig. 2.

Apart from the converter topology and the semiconductor used, the modulation technique may have a great impact on converter efficiency. Thus, we compare the efficiency of the converters when using a sinusoidal pulse width modulation

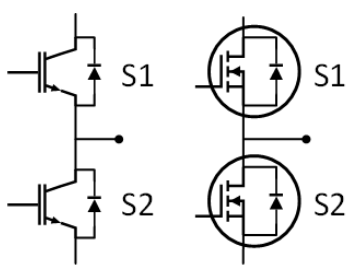

(a)

(b)

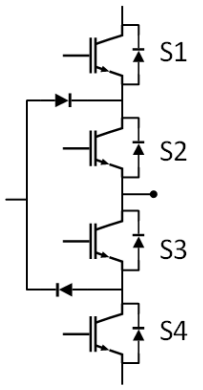

(a)

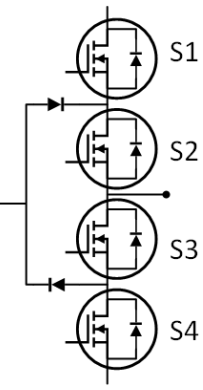

(b)

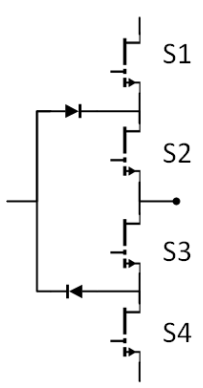

(c)

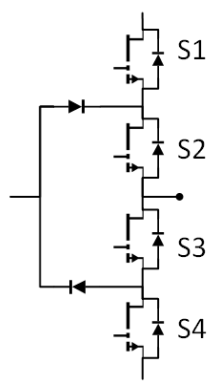

(d)
Fig. 2. Three-level half-bridge topologies: (a) Si IGBTs, (b) SiC MOSFETs, (c) GaN e-HEMTs with SiC clamping diodes, and (d) GaN e-HEMTs with $\mathrm{SiC}$ clamping and antiparallel diodes.

(SPWM) versus a modulation technique designed to minimize switching losses. The techniques designed to reduce converter losses are the discontinuous pulse width modulation (DPWM) [14], [15], for two-level converters, and the carrier based space vector pulse width modulation (CB-SVPWM) [16], for three-level converters. It is important to say that zero voltage switching is interesting for working at high switching frequencies [7], and using this technique may improve the performance of the converters and reduce EMIs. However, soft switching is out of the scope of this paper.

The rest of this paper is organized as follows. Section II explains the methods used to calculate the losses in the power devices used. Section III summarizes the applied modulation techniques. Section IV describes the electrical and the thermal models used to simulate the power converters and their power devices. Section V compares the efficiency of the different power converters, and Section VI concludes this paper.

\section{SEMICONDUCTOR LOSSES}

In power electronic devices there are mainly two types of losses: conduction losses and switching losses [11], [17], [18]. Conduction losses occur when the transistors are in the onstate, meaning when they are closed. The instantaneous value of conduction losses can be approximated as follows:

$$
P_{c l}=\frac{1}{T_{s w}} \int_{0}^{T_{s w}}\left(V_{F 0} \cdot i_{F}\right) d t
$$

where $V_{F 0}$ is the device threshold voltage, $i_{F}$ is the device current, and $T_{s w}$ is the switching period.

Switching losses occur when turning power devices on and off. Among WBG semiconductor technologies, GaN devices have no reverse recovery charge, so their switching losses are less than those using $\mathrm{Si}$ and $\mathrm{SiC}$ [19]. Measuring switching losses can be difficult [4], [19], [20], but they can be approximated using the following equation [17]:

$$
\begin{array}{r}
P_{s l}=\frac{1}{n T_{s w}} \sum_{j=1}^{j=n T_{s w}}\left[E_{o n_{j}}\left(v_{\text {block }}, i_{F}, T_{j}\right)+\right. \\
\left.+E_{o f f_{j}}\left(v_{\text {block }}, i_{F}, T_{j}\right)\right]
\end{array}
$$

Fig. 1. Two-level half-bridge topologies: (a) Si IGBTs and (b) SiC MOSFETs. 
in which $n T_{s w}$ is the number of transitions in one fundamental period and $E_{o n}$ and $E_{o f f}$ are the energy dissipated during the turn-on and turn off operations, respectively. These energies depend on the device blocking voltage $\left(v_{b l o c k}\right)$, the device current and the junction temperature $\left(T_{j}\right)$.

Nonetheless, some manufacturers provide equations to calculate more accurately the aforementioned losses in their devices. Equations (3), (4), (5) and (6) are provided by the manufacturer of the modelled GaN e-HEMTs.

$$
\begin{aligned}
& E_{\text {GaNon }}=g\left(E_{\text {on }}+\alpha\right) \\
& E_{\text {GaNoff }}=E_{\text {off }}+\beta \frac{25}{T_{j}} \\
& P_{s l}=E_{\text {GaNon }}+E_{\text {GaNoff }} \\
& P_{c l}=V_{F 0}-(1-g)\left(1.3-V_{G S_{o f f}}\right)
\end{aligned}
$$

where $E_{\text {GaNon }}$ and $E_{\text {GaNoff }}$ are the energy losses during turn-on and turn-off, respectively, $g$ is the gate signal and $V_{G S_{o} f f}$ is the voltage applied to the gate of the e-HEMT while turning-off. $\alpha$ and $\beta$ are defined in (7) and (8) in order to avoid making the former equations cumbersome.

$$
\begin{gathered}
\alpha=\frac{\left(R_{\text {gon }}-10\right)\left(\frac{v_{\text {block }} i_{f}}{2}\right)\left(3.4 \cdot 10^{-9}+\frac{4.4 \cdot 10^{-9} i_{F}}{63.44+i_{F}}\right)}{\left(4.7-\frac{i_{F}}{48.8}\right)} \\
\beta=\frac{\left(R_{\text {goff }}-2\right)\left(\frac{v_{\text {block }} i_{f}}{2}\right)\left(3.4 \cdot 10^{-9}+\frac{4.4 \cdot 10^{-9} i_{F}}{63.44+i_{F}}\right)}{\frac{i_{F}}{48.8}-V_{G S_{o f f}}-1.3}
\end{gathered}
$$

where $R_{\text {gon }}$ and $R_{\text {goff }}$ are the external turn-on and turn-off gate resistances.

For the considered $\mathrm{SiC}$ devices, the manufacturer provides the following expressions:

$$
\begin{aligned}
& E_{\text {SiCon }}=\frac{E}{5 a+b}\left(R_{g} a+b\right) \\
& E_{\text {SiCoff }}=\frac{E}{5 c-d}\left(R_{g} c-d\right) \\
& P_{s l}=E_{\text {SiCon }}+E_{\text {SiCoff }}
\end{aligned}
$$

in which, $E_{S i C o n}$ and $E_{S i C o f f}$ are the energy dissipated at the turn-on and turn-off of the device, respectively, $a=5.76 \cdot 10^{-5}$, $b=40.63 \cdot 10^{-5}, c=4.42 \cdot 10^{-5}, d=0.168 \cdot 10^{-5}$, and $R_{g}$ is the external gate resistance. Notice that these last equations do not differ between $R_{g o n}$ and $R_{g o f f}$.

Once we have conduction and switching losses, we can obtain total losses using:

$$
P_{t l}=P_{c l}+P_{s l}
$$

\section{Modulation Strategy}

Fig. 3 shows all the implemented modulation techniques. All these modulations are pulse width modulations in which the original modulation signals are modified to improve the performance. Modification of the original signal is carried out by adding a specific zero sequence [14], [16]. Each modulation injects a different zero sequence.

Fig. 3 (a) and Fig. 3 (b) illustrate the modulations used in twolevel converters. Both modulations increase the voltage gain by $15 \%$; therefore, they can virtually work with a modulation

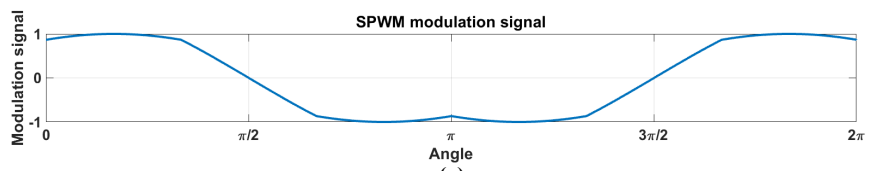

(a)
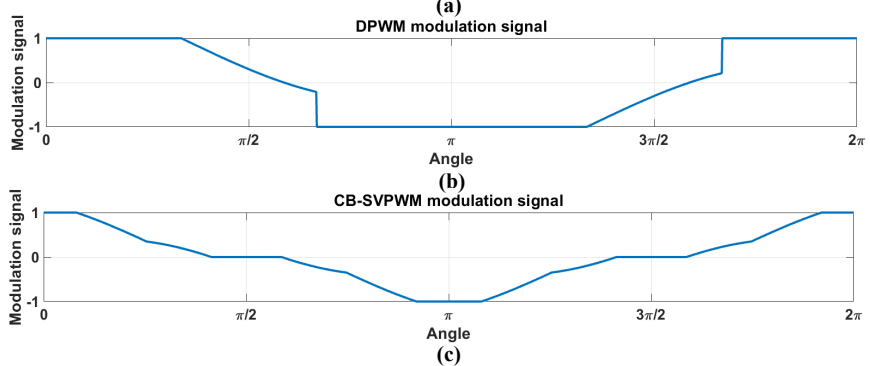

Angle
(c)

Fig. 3. Modulation signals: (a) Modified sinusoidal pulse width modulation, (b) Discontinuous pulse width modulation, and (c) Carrier-based space vector pulse width modulation

index of 1.15 [15]. The main difference between DPWM and SPWM is that the former clamps a phase, to the positive or the negative DC voltage during each carrier cycle [14]. Hence, DPWM produces less switching losses than SPWM.

Fig. 3 (a) and Fig. 3 (c) depict the modulation techniques implemented in three-level converters. SPWM is the same technique that is applied in two-level converters, but the modulation signal is compared with two unshifted carriers. One of these carriers goes from -1 to 0 while the other ranges from 0 to 1. CB-SVPWM was originally presented in [16]. As with DPWM, this technique clamps a phase during each carrier cycle and increases the linear-modulation range of the converter. Furthermore, CB-SVPWM is specifically designed to keep the capacitor voltages of the DC bus balanced [16].

\section{Simulation MOdel}

The proposed converter topologies and simulation techniques are evaluated in MATLAB/Simulink and PLECS blockset. In order to make a realistic model, we studied power converters that use real power devices available in the industry. The characteristics of these power devices are given in Table II.

The modelled system consists of a power converter connected to an ideal controlled load. This ideal load is composed of three current sources, one for each phase and connected in parallel with their own resistors.

Since the converter is not connected to the grid, their DC bus is modelled using ideal voltage sources. These sources allow keeping the DC bus voltage constant. Table III shows the parameters of the modelled circuit.

The goal of using PLECS is to obtain the thermal losses of the system. PLECS allows using thermal datasheets to calculate device losses, depending on several parameters such as the junction temperature, the device current or the device voltage. These thermal datasheets can be made manually from the component datasheet or it can be provided by the manufacturers. In the model used, all the thermal datasheets were provided by the different manufacturers. 
TABLE II

MODELLED CONVERTERS

\begin{tabular}{|c|c|c|c|}
\hline $\begin{array}{c}\text { Converter } \\
\text { topology }\end{array}$ & Power devices & Manufacturer & Model \\
\hline \multirow{2}{*}{ VSI } & Si IGBTs & ABB & 5SNG0150Q170300 \\
\hline & SiC MOSFETs & Cree & CCS050M12CM2 \\
\hline \multirow{7}{*}{ NPC } & Si IGBTs & Infineon & IKY75N120CH3 \\
\hline & SiC MOSFETs & Cree & CCS050M12CM2 \\
\hline & GaN e-HEMTs & GaN Systems & GS66516B \\
\hline & $\begin{array}{l}\mathrm{SiC} \text { clampling } \\
\text { diodes }\end{array}$ & Cree & CCS050M12CM2 \\
\hline & GaN e-HEMTs & GaN Systems & GS66516B \\
\hline & $\begin{array}{l}\mathrm{SiC} \text { clampling } \\
\text { diodes }\end{array}$ & Cree & CCS050M12CM2 \\
\hline & $\begin{array}{l}\mathrm{SiC} \text { antiparallel } \\
\text { diodes }\end{array}$ & Cree & CCS050M12CM2 \\
\hline
\end{tabular}

TABLE III

CIRCUIT PARAMETERS

\begin{tabular}{cc}
\hline \hline Parameters & Value \\
\hline DC Bus Voltage & $830 \mathrm{~V}$ \\
Load current & From $5 \mathrm{~A}$ to $30 \mathrm{~A}$ \\
Power rating & $27.72 \mathrm{kVA}$ \\
Junction temperature & $125^{\circ} \mathrm{C}$ \\
Switching frequency & From $50 \mathrm{kHz}$ to $500 \mathrm{kHz}$ \\
Modulation index & 0.9 \\
Current phase angle & $0^{\circ}$ or $150^{\circ}$ \\
External turn-on gate resistance ${ }^{\mathrm{a}, \mathrm{b}}$ & $10 \Omega$ \\
External turn-off gate resistance & $1 \Omega$ \\
Negative gate voltage & $-3^{\mathrm{a}} \mathrm{V}$ or $-5^{\mathrm{b}} \mathrm{V}$ \\
\hline \hline a Parameter only used in GaN e-HEMTs. & \\
b Parameter only used in SiC MOSFETs. &
\end{tabular}

Thermal datasheets define losses using look-up tables, equations or both. Look-up tables are similar to the loss tables provided on some component datasheets. In look-up tables, losses are defined for certain values of current, voltage and junction temperature. In addition, PLECS calculates the losses using linear interpolation if a device is working between two defined points. Fig. 4 and Fig. 5 are two examples of lookup tables used in the model: the first describes the turn-on losses of the SiC MOSFETs while the second defines their conduction losses.

Equations allow us to directly calculate the losses using parameters such as device voltage, current, junction temperature, and gate external resistance. Moreover, PLECS can use a look-up table to apply the calculated energy as an input variable for a formula. This operation allows obtaining a more accurate loss value. The equations that we used in our model - and provided in Section II - were obtained from the thermal datasheets.

\section{Simulation Results}

For this study, we perform four types of simulations. In order to simplify the nomenclature, the semiconductors are referred to by their chemical formula in the following plots. Henceforth, the GaN NPC converter that uses only SiC clamping diodes is simply named GaN. The other GaN NPC converter that uses both $\mathrm{SiC}$ clamping and antiparallel diodes

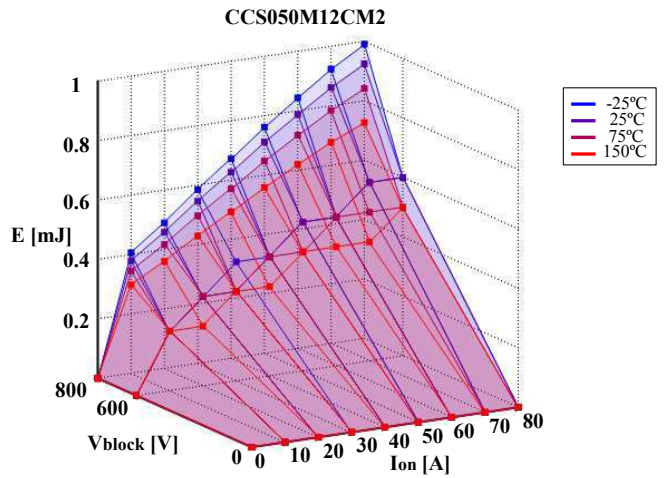

Fig. 4. Turn-on losses look-up table

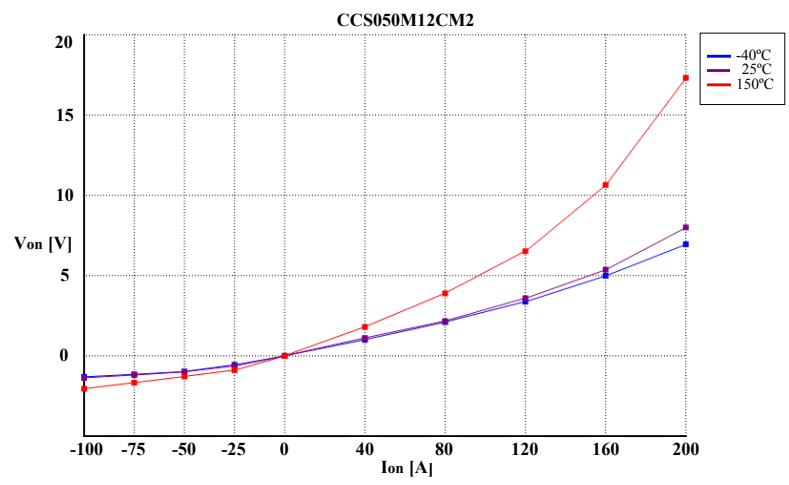

Fig. 5. Conduction losses look-up table

is called $\mathrm{GaN}-\mathrm{SiC}$.

The first simulations are detailed in Section V-A, and they compare the efficiency of two-level Si-based converters and $\mathrm{SiC}$-based converters. The second simulations, which are explained in Section V-B, compare the efficiency of two- and three-level converters using SiC MOSFETs. Then, in Section $\mathrm{V}-\mathrm{C}$, we compare the efficiency of three-level converters using $\mathrm{Si}$ and WBG semiconductors. Finally, in Section V-D, we analyse the impact of the current for SiC MOSFETs and GaN e-HEMTs.

\section{A. Comparing efficiency between two-level converters}

We compare the efficiency of two-level converters for a current phase angle of $0^{\circ}$ and a load current of $30 \mathrm{~A}$. The remaining circuit parameters are detailed in Table III.

Fig. 6 shows the losses in two-level converters for different switching frequencies. It is important to highlight that $\mathrm{Si}$ converters are not able to work at high frequencies. For this reason, we have simulated these converters while switching at a maximum of only $100 \mathrm{kHz}$.

In Fig. 6 we can observe that Si converters are always less efficient than SiC-based converters. Although Si conduction losses are slightly lower, their switching losses are extremely high compared with $\mathrm{SiC}$. Due to this characteristic, $\mathrm{SiC}$ converters switching at $500 \mathrm{kHz}$ have fewer losses than $\mathrm{Si}$ converters switching at $50 \mathrm{kHz}$. 


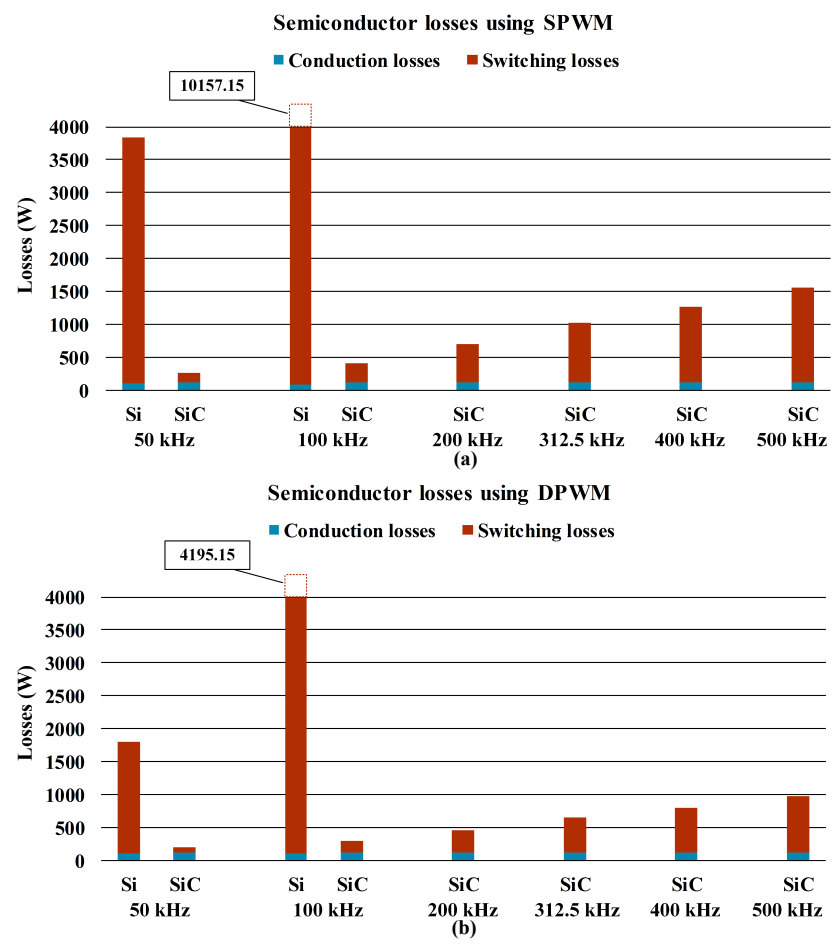

Fig. 6. Two-level converter losses: (a) using SPWM, and (b) using DPWM

Using DPWM reduces the switching losses of both types of converters. However, loss reduction is higher for Si-based converters. Thus, using a modulation technique that reduces switching losses always improves the converter efficiency, although its effect is not as significant in $\mathrm{SiC}$ as it is in $\mathrm{Si}$.

\section{B. Efficiency of SiC-based converters}

In this section, we study the efficiency of SiC-based converters and compare the losses produced by a VSI and an NPC converter, both of which use SiC MOSFETs. This analysis is performed for a current phase angle of $0^{\circ}$ and a load current of $30 \mathrm{~A}$. In regard to the modulations, the VSI converter uses DPWM while the NPC uses CB-SVPWM.

Fig. 7 shows the losses produced by the two aforementioned converters. Since three-level converters need more MOSFETs, their conduction losses are also higher. However, for all the studied frequencies, SiC-based NPC converters always produce less switching losses than VSIs.

Hence, at low frequencies, of up to $100 \mathrm{kHz}, \mathrm{SiC}$ experiences no significant switching losses. In fact, NPC converters at these frequencies have more conduction losses than switching losses. In therms of total losses, VSI converters are more efficient at low frequencies.

However, when the converters switch at high frequencies, switching losses constitute the majority of losses, which is why NPC converters exhibit the best performance.

\section{Comparing efficiency between three-level converters}

We compare the efficiency of three-level converters for a current of $30 \mathrm{~A}$ and a current phase angle of $0^{\circ}$. Fig. 8 (a)

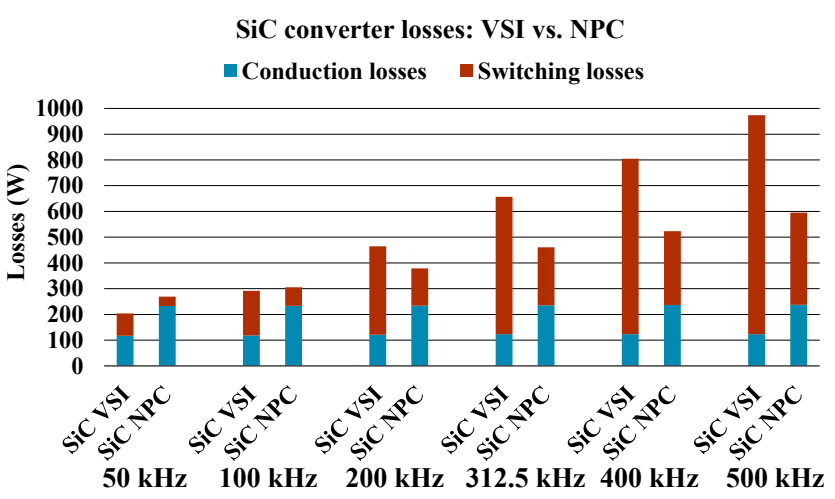

Fig. 7. Losses of SiC-based converters using DPWM and CB-SVPWM

shows the losses produced using SPWM while Fig. 8 (b) depicts the losses using CB-SVPWM. Si converters are only studied for frequencies of up to $100 \mathrm{kHz}$, due to their switching limitations.

$\mathrm{GaN}$ conduction losses are higher than $\mathrm{SiC}$ conduction losses. $\mathrm{GaN}-\mathrm{SiC}$ exhibits slightly less conduction losses than $\mathrm{GaN}$, but their switching losses are somewhat worse. For all the studied modulations, $\mathrm{SiC}$ converters are more efficient up to $400 \mathrm{kHz}$. However, at higher frequencies, the inferior switching losses of $\mathrm{GaN}$ and $\mathrm{GaN}-\mathrm{SiC}$ begin to be relevant. At $500 \mathrm{kHz}$ the performance of $\mathrm{SiC}, \mathrm{GaN}$, and $\mathrm{GaN}-\mathrm{SiC}$ is similar, $\mathrm{GaN}$ converters are better when using SPWM but the SiC NPC is better when using CB-SVPWM.

Due to the similarity of the results at high frequencies, the results obtained from this analysis can be misleading. In order to obtain conclusive data, we study the behaviour of WBG semiconductors at $500 \mathrm{kHz}$ for all the modulation indices and all the current phase angles. The modulation used is CBSVPWM, since it is the most efficient, and the total loss ratios obtained are shown in Fig. 9.

Fig. 9 (a) illustrates the ratio between the total losses of $\mathrm{SiC}$ to GaN. The point previously studied, $m=0.9$ and $\Phi=0$, is the only one at which SiC converters exhibit slightly better performance than GaN converters. For the rest of the modulation indices and current phase angles, the performance of GaN-based converters is better.

Fig. 9 (b) depicts the total loss ratio of $\mathrm{GaN}-\mathrm{SiC}$ to $\mathrm{GaN}$. The efficiency of both converters is mostly equal. Nevertheless, GaN-SiC exhibits better performance when the converter works with highly shifted currents.

Finally, Fig. 9 (c) shows the loss ratio between $\mathrm{SiC}$ and $\mathrm{GaN}$ $\mathrm{SiC}$. As in Fig. 9 (a), the performance of the $\mathrm{SiC}$ converter is equal, or even better, when it works with high modulation indices and unshifted currents. Otherwise, GaN-SiC is more efficient.

\section{Current impact on efficiency}

From the previous results, we can state that SiC-based converters have fewer conduction losses than $\mathrm{GaN}$ converters but $\mathrm{GaN}$ and GaN-SiC NPCs have less switching losses. In order to determine when $\mathrm{SiC}$ is better than $\mathrm{GaN}$, or vice versa, 


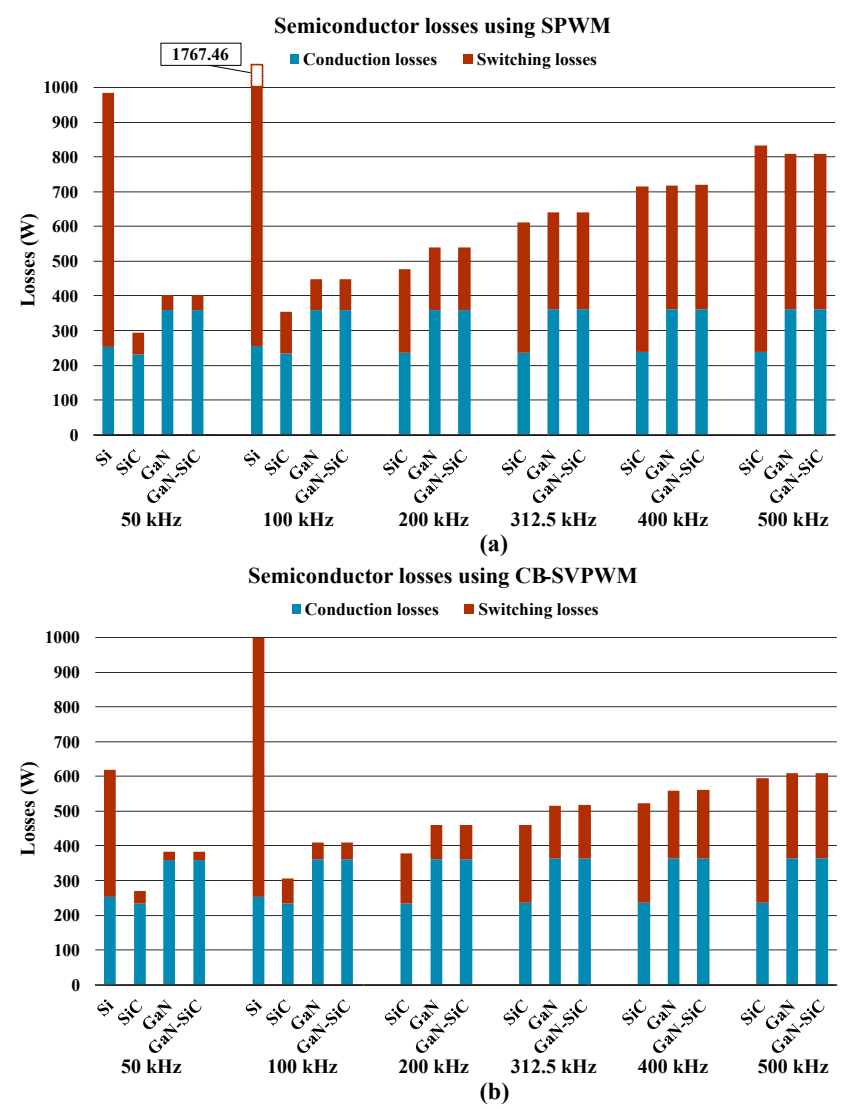

Fig. 8. Three-level converter losses: (a) SPWM, and (b) CB-SVPWM

we study the effect of current on total losses. We simulate $\mathrm{SiC}, \mathrm{GaN}$ and GaN-SiC NPC converters using different load currents. In addition, we perform the same analysis for different switching frequencies. In these scenarios, the modulation index is 0.9 and the current phase angle is $150^{\circ}$. Fig. 10 shows the obtained results. Notice that the black dots indicate the point where one topology surpasses another.

$\mathrm{GaN}$ and $\mathrm{GaN}-\mathrm{SiC}$ have similar behaviours, but $\mathrm{GaN}$ has fewer losses at low currents of up to $20 \mathrm{~A}$. At higher currents, $\mathrm{GaN}$ losses begin to increase rapidly. This behaviour seems to be independent of the switching frequency and the modulation technique.

In the studied range of currents, $\mathrm{SiC}$ never surpasses $\mathrm{GaN}$ $\mathrm{SiC}$. GaN-SiC always has fewer losses than $\mathrm{SiC}$. However, the results obtained suggest that $\mathrm{SiC}$ may be better when working at currents higher than $30 \mathrm{~A}$. This behaviour can easily be observed in Fig. 10 (a) and Fig. 10 (b).

The point at which $\mathrm{SiC}$ surpasses $\mathrm{GaN}$ heavily depends on the switching frequency. At $50 \mathrm{kHz}$, this point is around $23 \mathrm{~A}$ while at $500 \mathrm{kHz}$ the point is located above $30 \mathrm{~A}$. The CB-SVPWM modulation reduces switching losses and, thus, allows $\mathrm{SiC}$ to surpass $\mathrm{GaN}$ at slightly lower currents.

\section{CONClusions}

This paper analyses power converters based on $\mathrm{Si}$ and WBG semiconductors. Consequently, it helps determine which

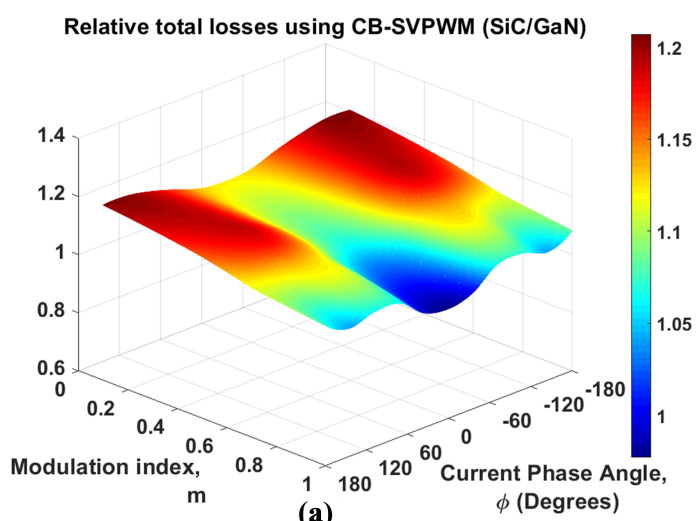

(a)

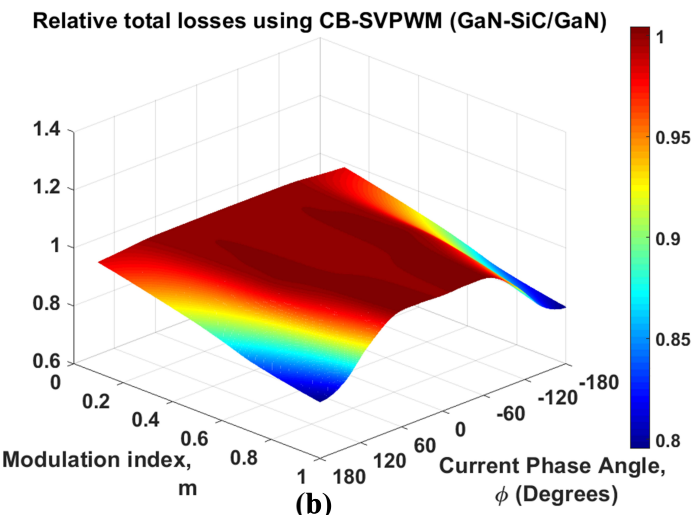

Relative total losses using CB-SVPWM (SiC/GaN-SiC)

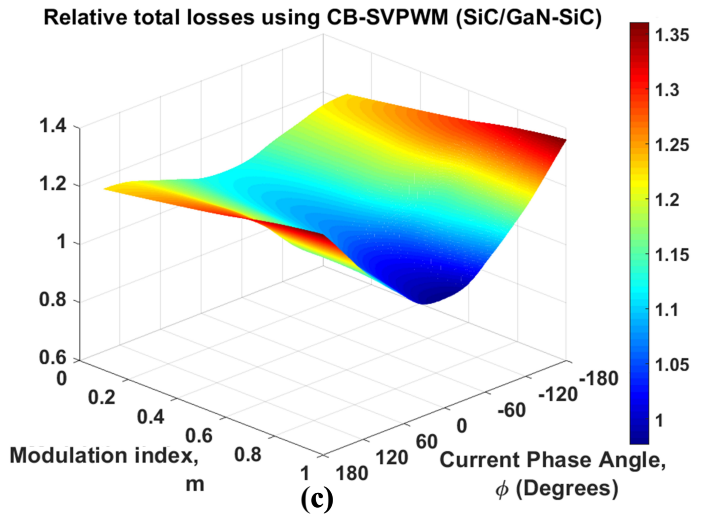

Fig. 9. Ratio of the resultant total losses of: (a) $\mathrm{SiC}$ to $\mathrm{GaN}$, (b) GaN-SiC to $\mathrm{GaN}$, and (c) $\mathrm{SiC}$ to $\mathrm{GaN}-\mathrm{SiC}$

semiconductor is better for a specific operating condition. Two-level SiC converters are always more efficient than the classic Si-based VSIs. Using a modulation technique that minimises switching losses improves the performance of $\mathrm{SiC}$ converters, but the obtained improvement is worse than that of Si converters. SiC VSIs exhibit better performance than SiC NPCs when working at frequencies of up to $100 \mathrm{kHz}$. For higher frequencies, SiC NPCs are more efficient. A proper comparison between $\mathrm{SiC}$ and $\mathrm{GaN}$ depends on several factors such as the operating point, the switching frequency, and the current. In general, GaN-based converters seem to be the best option in terms of efficiency, particularly when working at high switching frequencies or using low currents. However, 


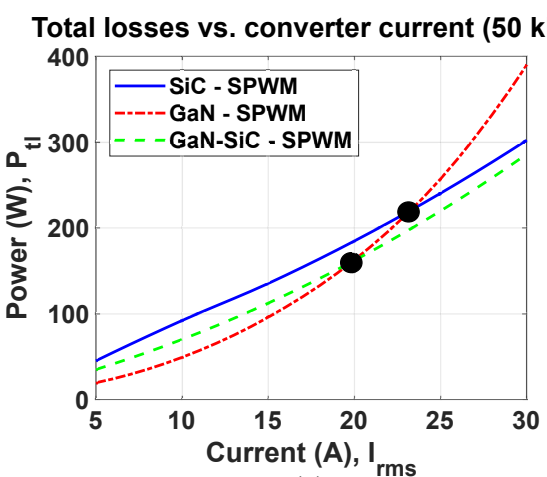

(a)

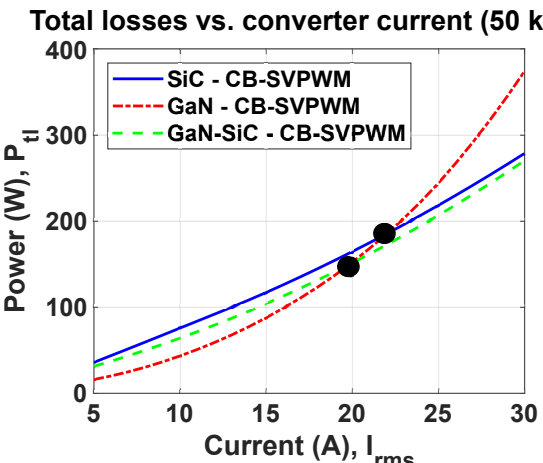

(d)

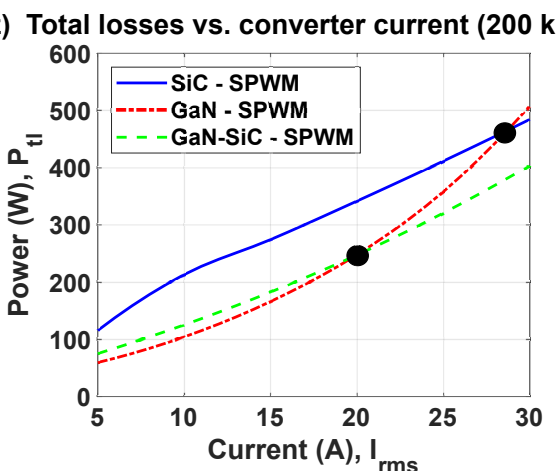

(b)

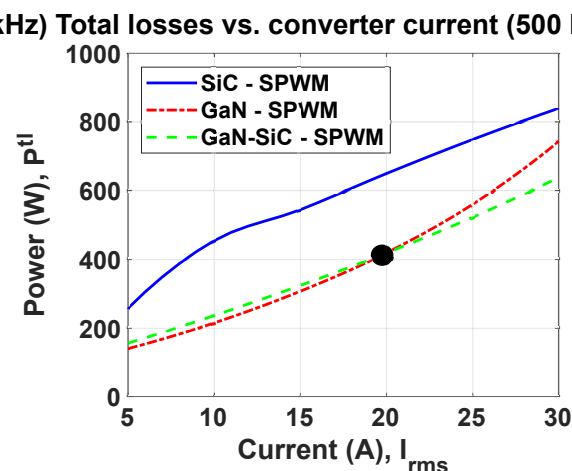

(c)

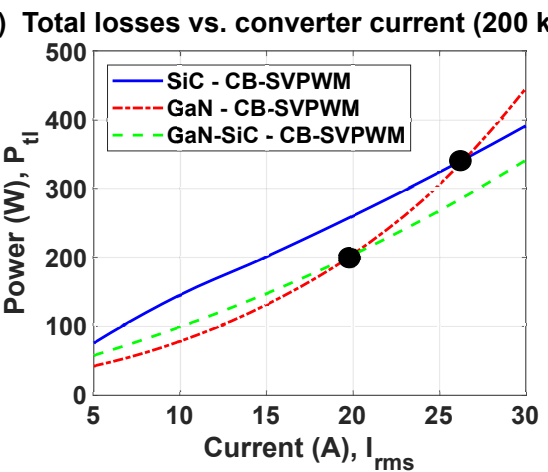

(e)

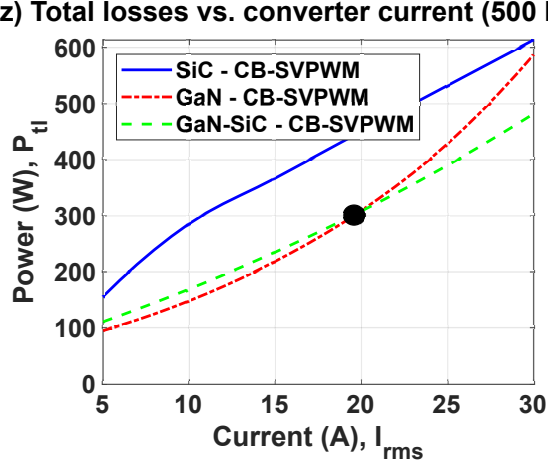

(f)

Fig. 10. Total losses vs. load current of NPCs using: (a) SPWM at $50 \mathrm{kHz}$, (b) SPWM at $200 \mathrm{kHz}$, (c) SPWM at $500 \mathrm{kHz}$, (d) CB-SVPWM at $50 \mathrm{kHz}$, (e) CB-SVPWM at $200 \mathrm{kHz}$, and (f) CB-SVPWM at $500 \mathrm{kHz}$.

$\mathrm{SiC}$ converters may be better when we need to work with high currents. Additionally, we can add antiparallel SiC diodes to GaN e-HEMTs in order to reduce the conduction losses. These diodes provide an intermediate solution between $\mathrm{GaN}$ and $\mathrm{SiC}$. They reduce conduction losses but also increase switching losses. The simulation results show that this proposed topology improves the performance at high currents but increases the losses when the currents are low. This topology can be a good solution for working at high frequencies with high currents.

\section{ACKNOWLEDGEMENT}

This work was supported by the Industrial Doctorates Plan of the Secretaria d'Universitats i Recerca del Departament d'Empresa i Coneixement de la Generalitat de Catalunya.

\section{REFERENCES}

[1] E. A. Jones, F. F. Wang, and D. Costinett, "Review of Commercial GaN Power Devices and GaN-Based Converter Design Challenges," IEEE Journal of Emerging and Selected Topics in Power Electronics, vol. 4, no. 3, pp. 707-719, 2016.

[2] T. Paul Chow, "Wide bandgap semiconductor power devices for energy efficient systems," WiPDA 2015 - 3rd IEEE Workshop on Wide Bandgap Power Devices and Applications, pp. 402-405, 2015.

[3] B. Ozpineci and L. M. Tolbert, Comparison of wide-bandgap semiconductors for power electronics applications. Oak Ridge, Tennessee: UT-BATTELLE, 2003.

[4] J. Xu, Y. Qiu, D. Chen, J. Lu, R. Hou, and P. D. Maso, “An Experimental Comparison of GaN E- HEMTs versus SiC MOSFETs over Different Operating Temperatures," 2017.
[5] G. Deboy, M. Kasper, A. M. Garcia, and M. Schlenk, "The Promise of GaN in Light of Future Requirements for Power Electronics," CIPS 2018; 10th International Conference on Integrated Power Electronics Systems, pp. 1-7, 2018.

[6] J. Millan, P. Godignon, X. Perpina, A. Perez-Tomas, and J. Rebollo, "A survey of wide bandgap power semiconductor devices," IEEE Transactions on Power Electronics, vol. 29, no. 5, pp. 2155-2163, 2014.

[7] J. L. Lu, R. Hou, and D. Chen, "Opportunities and design considerations of GaN HEMTs in ZVS applications," Conference Proceedings - IEEE Applied Power Electronics Conference and Exposition - APEC, vol. 2018-March, pp. 880-885, 2018.

[8] M. Ferdowsi, P. Shamsi, and B. Baddipadiga, "Gallium Nitride ( GaN ) based High Frequency Inverter for Energy Storage Applications."

[9] T. P. Chow, "Progress in High Voltage $\mathrm{SiC}$ and GaN Power Switching Devices," Materials Science Forum, vol. 778-780, pp. 1077-1082, 2014.

[10] R. S. Pengelly, S. M. Wood, J. W. Milligan, S. T. Sheppard, and W. L. Pribble, "A Review of $\mathrm{GaN}$ on $\mathrm{SiC}$ High Electron-Mobility Power Transistors and MMICs," vol. 60, no. 6, 2012.

[11] A. Wintrich, U. Nicolai, W. Tursky, and T. Reimann, Application Manual Power Semiconductors, 2nd ed. Semikron.

[12] B. De Jaeger, M. Van Hove, D. Wellekens, X. Kang, H. Liang, G. Mannaert, K. Geens, and S. Decoutere, "Au-free CMOS-compatible $\mathrm{AlGaN} / \mathrm{GaN}$ HEMT processing on $200 \mathrm{~mm}$ Si substrates," Proceedings of the International Symposium on Power Semiconductor Devices and ICs, no. June, pp. 49-52, 2012.

[13] PRNewswire, "VisIC Technologies Partners With TSMC to Offer Industry's Most Advanced 1200V GaN-based Power Device Solutions," 2018. [Online]. Available: https://en.prnasia.com/releases/apac/visictechnologies-partners-with-tsmc-to-offer-industry-s-most-advanced1200v-gan-based-power-device-solutions-202102.shtml

[14] A. M. Hava, S. Member, R. J. Kerkman, and T. A. Lipo, "A HighPerformance Generalized Discontinous PWM Algorithm," IEEE Transactions on Industry Applications, vol. 34, no. 5, pp. 1059-1071, 1998.

[15] R. Picas, S. Ceballos, J. Pou, J. Zaragoza, G. Konstantinou, and V. G. Agelidis, "Improving capacitor voltage ripples and power losses of mod- 
ular multilevel converters through discontinuous modulation," IECON Proceedings (Industrial Electronics Conference), no. 1, pp. 6233-6238, 2013.

[16] J. Pou, J. Zaragoza, S. Ceballos, M. Saeedifard, and D. Boroyevich, "A carrier-based PWM strategy with zero-sequence voltage injection for a three-level neutral-point-clamped converter," IEEE Transactions on Power Electronics, vol. 27, no. 2, pp. 642-651, 2012.

[17] J. Zaragoza Bertomeu, "Modulation strategies for the neutral-pointclamped converter and control of a wind turbine system," Ph.D. dissertation, Universitat Politècnica de Catalunya, 2011. [Online]. Available: http://www.tdx.cat/handle/10803/130900

[18] K. Rouzbehi, M. Davarifar, M. Martino, C. Citro, A. Luna, Z. Daneshifar, and P. Rodriguez, "Comparative efficiency study of single phase photovoltaic grid connected inverters using PLECS $®$," 2nd International Congress on Technology, Communication and Knowledge, ICTCK 2015, no. Ictck, pp. 536-541, 2016.

[19] R. Hou, J. Lu, and D. Chen, "Parasitic capacitance Eqoss loss mechanism, calculation, and measurement in hard-switching for GaN HEMTs," Conference Proceedings - IEEE Applied Power Electronics Conference and Exposition - APEC, vol. 2018-March, pp. 919-924, 2018.

[20] GaN Systems, "GN003 Application Note. Measurement Techniques for High-Speed GaN E-HEMTs,” Tech. Rep. August, 2018. 